\title{
LA INTERACCIÓN DE LOS CÓDIGOS EN DOBLAJE: JUEGOS DE PALABRAS Y RESTRICCIONES VISUALES $^{1}$
}

\author{
Anjana Martínez Tejerina \\ Universitat Pompeu Fabra (España) \\ anjana.martinez@upf.edu
}

\section{Resumen}

El siguiente artículo profundiza en la complejidad del trasvase del humor, basándose en un problema recurrente en el doblaje de comedias: los juegos de palabras transmitidos parcialmente a través de la imagen. El estudio analiza los factores que inciden en su traducción e ilustra las distintas técnicas de traducción con escenas de la filmografía de los Hermanos Marx. Finalmente, muestra las conclusiones obtenidas a partir del análisis del doblaje de 74 juegos de palabras con restricción visual y su comparación con 116 casos en los que no hay dicha restricción.

\begin{abstract}
"The interaction of codes in dubbing: wordplay and visual restrictions."

The following paper delves into the complex transfer of humour, focusing on a recurring problem that appears when dubbing comedies: wordplay partially conveyed by image. It analyses the factors that have a bearing on translation and illustrates the various translation techniques with scenes from the Marx Brothers' filmography. Finally, it details the conclusions obtained from the analysis of the dubbing of 74 puns with visual restriction and its comparison with 116 cases where there is no such restriction.
\end{abstract}

1. Esta investigación ha sido posible gracias al proyecto "La subtitulación para sordos y la audiodescripción: pruebas objetivas y planes de futuro" (2009-2012), financiado por el Ministerio de Ciencia e Innovación de España (FFI2009-08027), y a los fondos de la Generalitat Catalana 2009SGR700. 
Palabras clave: Traducción audiovisual. Doblaje. Humor. Juegos de palabras. Restricciones visuales.

Keywords: Audiovisual translation. Dubbing. Humour. Wordplay. Visual restrictions.

Manuscript received on June 29, 2011; Definitely accepted on November 15, 2011. 


\section{Introducción}

Una de las características que diferencia al texto audiovisual de otro tipo de textos es que el mensaje se transmite a través de distintos canales, a saber, el auditivo y el visual. El espectador recibe estímulos a través de dos fuentes de información que, por lo general, se complementan en la creación de significados. La mayoría de las veces la imagen ayuda en el proceso de traducción, tanto a la hora de comprender los elementos de la versión original como a la hora de trasvasarlos, ya que parte de la información aparece en la imagen y, por tanto, no es necesario explicitarla en la traducción. Sin embargo, en ocasiones, esta conjunción de códigos genera problemas, como en el caso de los juegos de palabras combinados con humor visual, en donde se explota precisamente esa diversidad de canales de información para transmitir cargas semánticas dispares y lograr así un contraste entre lo que se oye y lo que se ve. Teniendo en cuenta que el traductor sólo modifica uno de esos canales, el que no se puede alterar, es decir, la imagen, será el que se imponga y limite su margen de maniobra. ¿A qué técnicas ${ }^{2}$ recurre el traductor cuando su prioridad es trasvasar el efecto humorístico pero éste se basa en la manipulación lingüística y la explotación simultánea de los canales auditivo y visual?

El presente artículo intenta responder a esta pregunta y para ello analiza 74 ejemplos, seleccionados de los 240 estudiados en un estudio anterior de carácter más general (Martínez-Tejerina 2008), en los que aparecen juegos de palabras con restricciones visuales. El análisis compara la versión original en inglés con la versión doblada en castellano de las trece películas que conforman la filmografía completa de los Hermanos Marx (Groucho, Chico y Harpo). Evidentemente, aunque las conclusiones harán referencia a los 74 casos, debido a la extensión limitada del presente artículo, sólo se muestran 6 ejemplos a modo de ilustración.

2. La noción de "técnica de traducción" queda reservada en palabras de Hurtado Albir (2001: 256-257) "para referirnos al procedimiento verbal concreto, visible en el resultado de la traducción, para conseguir equivalencias traductoras." 


\section{Humor y juegos de palabras basados en polisemia}

Los juegos de palabras basados en polisemia explotan la similitud formal de estructuras lingüísticas que difieren en el plano semántico. Esta combinación de palabras que se asemejan formalmente pero cuyos significados son ajenos rompe las expectativas del espectador, lo que causa sorpresa y le hace oscilar entre dos interpretaciones:

All humour, and much intelligence, entails an ability to think on two plans at once. $[\ldots]$ In the pun, there are always two or more levels, manifest and latent, in some kind of coexistence, sequence, alternation or tension. [...] The key movement of the pun is pivotal [...] This pivotal wordplay enables the story to bifurcate $[\ldots]$ it generally involves a shift of emphasis. (Redfern 1984: 26-27)

Según las teorías de la incongruencia (cf. Raskin 1985; Attardo \& Raskin 1991), el elemento sorpresa es primordial en la creación del chiste, el humor surge de un conflicto entre lo que se espera y lo que ocurre, la incongruencia se desarrolla entre dos ideas, conceptos o situaciones dispares y relacionados de forma sorprendente o imprevista. Así, en los juegos de palabras, una ambigüedad deliberada en la fonología, grafología, morfología, léxico o sintaxis (denominada trigger o detonante) induce a error y despista a la audiencia hasta que el punchline (frase clave, clímax o remate del chiste) resuelve el conflicto. La oposición puede desarrollarse en diferentes ámbitos: real-irreal, verdadero-falso, normal-anormal, posible-imposible, bueno-malo, vida-muerte, sexo-no sexo, etc.

Al mismo tiempo, son necesarios otros elementos para que el juego de palabras cumpla su función con éxito. En primer lugar, la adaptación y verosimilitud al contexto. En segundo lugar, lo que Freud (1905: 45) denomina el "desplazamiento del acento psíquico". En otras palabras, la desviación del proceso mental hacia un tema distinto del iniciado, hacia un círculo de representación lejano. Además, Freud (1905: 106) añade que el placer producido por el juego de palabras aumentará cuanto mayor sea el desplazamiento, es decir, cuanto más extraños sean entre sí los dos círculos de representación enlazados por la palabra y, por tanto, cuanto mayor sea el ahorro de camino mental procurado por el chiste.

En conclusión, cuanta mayor verosimilitud y naturalidad presenten ambas lecturas en un contexto determinado y cuanto más lejanas sean a su vez dichas realidades, mayor será el efecto lúdico. 


\section{La semiótica del texto audiovisual: la interacción de los códigos y las restricciones visuales}

Como decíamos anteriormente, el texto audiovisual se caracteriza fundamentalmente por la transmisión simultánea del mensaje a través de distintos canales y códigos. Precisamente, una de sus características más notoria y específica es "el significado extra" (Chaume 2004: 26) o "la valeur ajoutée" (Chion 1990: 205) que se produce mediante la interacción de los diferentes códigos en cada momento. Es decir, cada código expresa significado y la interacción de los mismos provoca un significado añadido. Todos estos códigos tienen importancia en el conjunto e influyen en la interpretación del texto audiovisual; es más, Chaume (2004: 26) subraya que "el código lingüístico, pese a su papel preponderante, es sólo un código más en juego en la construcción y posterior trasvase de los textos audiovisuales".

La diversidad de códigos que compone el texto audiovisual tiene dos resultados opuestos. En algunas ocasiones, puede favorecer la comprensión del espectador meta (y del traductor) gracias a la gran aportación semiótica que ofrecen los diversos códigos emitidos de forma simultánea (Martínez Sierra 2008). En otras ocasiones, puede limitar y entorpecer la labor traductora debido a las dificultades que surgen en el trasvase interlingüístico de un producto que abarca diferentes códigos portadores de información y de los que sólo se puede modificar uno. Por lo tanto, es la imagen, al no poder ser modificada, la que impone las restricciones temporales, espaciales y, en el caso que nos ocupa, semánticas. Esta presencia física de elementos de la versión original en la traducción es denominada "total or partial co-ocurrence of the original" (Gottlieb 2005: 88). Ante este fenómeno, se produce un acuerdo tácito en el que el espectador acepta lo inverosímil (suspension of disbelief); por ejemplo, que un actor extranjero hable un perfecto español.

Evidentemente, todos los diálogos de un texto audiovisual están vinculados en mayor o menor grado a lo que sucede en pantalla, pero distinguimos como restricciones visuales aquellas imágenes que supeditan al texto. Aplicado a los juegos de palabras, esto supone una diferenciación clara entre aquellos relativamente independientes de los elementos visuales en pantalla y aquellos vinculados inextricablemente al código visual. Estos últimos consisten en la reiteración de una palabra (o del componente de imagen de una unidad fraseológica) con su referente icónico y viceversa, esto es, parte del mensaje se expresa a través de la palabra y parte del mensaje, a través de la imagen. Chaume (2004: 238-243) denomina a este fenómeno recurrencia o reiteración de tipo intersemiótico y comenta: 
La recurrencia semiótica se produce cuando dos códigos aportan la misma información simultáneamente. Los problemas surgirán cuando la traducción de las palabras (su equivalente acuñado en lengua meta) no haga ninguna referencia a la información transmitida por otros códigos. [...] En un estadio más complicado, la recurrencia puede incluso aparecer junto a juegos de palabras. En estos casos, el código lingüístico puede hacer referencia a uno de los significados del juego de palabras y el código iconográfico al otro significado de la figura estilística.

En los giros contextuales provocados por la imagen, una de las acepciones del término se evoca a través de la escena, ya sea por medio de actos o de objetos. De este modo, aparecen en pantalla dos lecturas diferentes de la misma palabra o unidad fraseológica, creando una contradicción entre el código lingüístico y el iconográfico. La imagen muestra la carga semántica inesperada, lo que genera el efecto humorístico. Huelga decir que la restricción será mayor cuanto más visible sea la carga semántica expresada por la imagen. Esta observación aparentemente obvia insiste en la necesidad de comprender y valorar la semiótica fílmica, pues en este caso la planificación se erige como un factor primordial para el trasvase del código lingüístico. Por ejemplo, en la filmografía de los Marx encontramos secuencias en las que el objeto se muestra en un primer plano y otras en las que un plano medio impide que el objeto se vea con claridad. El primer caso se observa en una secuencia de Plumas de caballo (Horse Feathers, 1932) en la que Groucho advierte a Harpo: "Young man, as you grow older you'll find that you can't burn the candle at both ends" y Harpo, a modo de respuesta, muestra en primer plano una vela encendida por ambos extremos. El segundo caso se desarrolla en una escena de Los Hermanos Marx en el Oeste (Go West, 1940) en la que un hombre de negocios, cansado de intentar llegar a un trato con una persona tan absurda como Groucho, exclama: "I wash my hands on this whole deal!"; a lo que Groucho replica lanzándole una pastilla de jabón: "Try this soap. We are having a special on it." No obstante, el plano entero impide una visión clara de la pastilla por lo que, en caso de que no hubiera habido paralelismo etimológico y el traductor hubiese querido trasvasar la carga humorística, podría haber basado su juego de palabras en cualquier objeto similar al que se ve en pantalla, sin necesidad de que se mencionara obligatoriamente el jabón.

Otra curiosidad de la relación que se establece entre planificación y juegos de palabras en el texto audiovisual es la posibilidad de utilizar un plano medio para incluir en la misma imagen tanto el contexto primario, como el clímax fruto del giro contextual. Es muy probable que esta decisión no fuera intencionada en la filmografía de los Marx y que se debiera más bien a las convenciones de la época y a las reminiscencias teatrales. En cualquier caso, el 
uso de este tipo de planos por un lado invita a la comedia de enredo y de situación y, por otro, fomenta la aparición en pantalla de las dos cargas semánticas del juego de palabras. Esta característica se puede observar en una hilarante secuencia de Plumas de caballo (Horse Feathers, 1932) en la que Groucho y Chico intentan firmar un acuerdo, pero no encuentran lo que necesitan para legalizarlo, por lo que exclaman insistentemente: "Wait a minute. Wait a minute. This isn't legal. There's no seal on it. Where's the seal?" Harpo trae una foca. En esta escena, el uso de un plano medio permite incluir en la misma imagen tanto el contexto de una de las cargas semánticas (un despacho de abogados), como la representación de la carga inesperada (el animal).

Como mencionábamos anteriormente, estas restricciones visuales -el hecho de que la imagen refuerce, niegue, complemente o matice el mensaje expresado por el código oral- pueden suponer un obstáculo para el trasvase traductor. Chaume (2004: 27) comenta que el traductor tiende a expresar el sentido que irrumpe como fruto de la interacción de los códigos, pero que a veces queda atado por el sema que transmite la imagen de tal manera que se limita a evitar que lo que se dice contradiga a lo que se ve.

Por otro lado, el traductor intenta superar todos estos obstáculos sin que su labor quede explícita en la versión doblada, pues ésta se valora con frecuencia por el grado de invisibilidad del mismo. Autores como Agost (1999: 52), Castro (2001: 42) o Brehm (2005: 190) coinciden en que la traducción debe pasar inadvertida; en otras palabras, el trasvase habrá tenido éxito si el espectador no se da cuenta de que está viendo un doblaje.

\section{Humor y doblaje}

En la traducción audiovisual (TAV) del humor inciden numerosos factores. En este apartado comentamos primero factores más generales -como pueden ser las barreras y coincidencias entre culturas, la capacidad comunicativa del medio audiovisual o la naturaleza de la industria cinematográfica- para después analizar características lingüísticas que afectan al trasvase del humor.

\subsection{El doblaje de las comedias}

El doblaje de comedias de situación se desarrolla a diario y, en general, de modo satisfactorio. Este éxito de las comedias extranjeras se debe, entre otros factores, a las coincidencias humorísticas entre culturas, a los aciertos de las traducciones y a la capacidad comunicativa del medio audiovisual.

En primer lugar, la audiencia meta ríe debido a rasgos humorísticos comunes a las culturas en juego: ya sean recursos cómicos universales como las 
caídas o las batallas de tartas, coincidencias culturales (las diferencias no son tan abismales como podría augurarse, especialmente si las sociedades son la estadounidense y la española) o la alusión a costumbres o referentes culturales conocidos (por ejemplo, personajes célebres como Obama o instituciones como la Casa Blanca). Por fortuna para el traductor, la globalización y la predominancia actual de los Estados Unidos en todos los campos -entre ellos, el cinematográfico- facilita considerablemente el reconocimiento de signos y símbolos de la cultura de origen.

En segundo lugar, huelga decir que una traducción eficaz es capaz de salvar la mayoría de las dificultades que surgen en la traducción del humor o, por lo menos, de compensarlas. Además, no hay que olvidar que España destaca precisamente por la calidad de sus doblajes.

En tercer lugar, la capacidad comunicativa del medio audiovisual llega a restar importancia al proceso traductor. Comentando las posibilidades de trasvase de las comedias, Rabadán (1991) afirma que la literatura cómica no viaja, mientras que Díaz-Cintas (2003: 254) asegura que las películas sí lo hacen:

[...] las razones de esta discrepancia entre la traducción de programas audiovisuales y literatura de naturaleza cómica han de ser forzosamente múltiples. Una de ellas es, sin duda, la gran aportación semiótica de la imagen, que en pocas ocasiones está jerarquizada por encima de la palabra y hace que el humor viaje mejor en formato audiovisual.

Algunos autores relativizan su trascendencia debido al contexto en el que se enmarca y a la multitud de factores que afectan a la recepción del texto audiovisual:

Comic films are successful in many cultures, yet for different reasons. Translation must surely play an important role. However, even if we may quite safely hypothesize that quality of translation can either make or break a comedy, it is only one single factor among many which contributes to a film's success $[\ldots]$ such as the actors, screenplay, other films on the circuit at a particular moment in time, socio-economic factors regarding audiences, advertising campaigns, and the psychological state of spectators themselves. (Chiaro 2006: 205-206).

A pesar de lo dicho, debemos reconocer que las películas cómicas tropiezan con multitud de barreras lingüísticas y culturales que, en ocasiones, no logran salvar y que provocan la extrañeza o desapego de la audiencia meta. Chiaro (2000) advierte de que el éxito de la mayoría de los humoristas se reduce a su círculo cultural. La autora se pregunta si una posible causa de ello es el uso de juegos de palabras, comparando dichas películas con otras de más éxito como Un pez llamado Wanda (A Fish Called Wanda, 1988), Cuatro bodas y un funeral 
(Four Weddings and a Funeral, 1994), o Full Monty (The Full Monty, 1997), que contienen muy pocos puns y que se basan en situaciones cómicas, parodias y otros tipo de humor que no están relacionados con la ambigüedad lingüística:

Thus, we could begin to hypothesize that humor on screen tends to be more successful within the borders of its country of origin and less successful abroad when the type of wordplay it contains is of the punning variety simply because of translational difficulty (Chiaro 2005: 138).

Es importante subrayar que el efecto perlocutivo del texto meta cobra aún más importancia en traducción audiovisual y, concretamente, en la cinematográfica, ya que el cine es una industria y, en consecuencia, la reacción del cliente (la audiencia) es extremadamente importante por razones económicas y de mercado. A este respecto, cabe mencionar que en TAV las normas parecen más explícitas que en otros tipos de traducción por un motivo fundamental: el texto audiovisual se concibe como un producto comercial que debe ser consumido; en consecuencia, el receptor, es decir, el consumidor, adquiere mayor relevancia y sus gustos y prioridades son fundamentales. Ivarsson (1992: 66) señala que "viewers are creatures of habit", lo que implica que se debe respetar aquello a lo que esté acostumbrada la audiencia.

Autores como Whitman (2001) consideran que los productores estadounidenses sólo tienen en cuenta a la audiencia local, mientras que otros (Delabastita 1989; Chaves 2000; o Martínez Sierra 2008) aseguran que la producción de muchas películas considera los posibles objetivos de mercado en el presente contexto de globalización económica y cultural, en otras palabras, los filmes se producen con el objetivo de llegar a un amplio mercado internacional. En nuestra opinión, muchas películas y series, sobre todo las grandes producciones, aspiran a alcanzar efectivamente un éxito internacional, para lo que utilizan estrategias como la promoción y la mercadotecnia. Sin embargo, la mayoría de estas películas incluyen referencias culturales y juegos de palabras cuya comicidad puede perderse en el trasvase lingüístico a causa de la falta de conocimientos compartidos y a las características intrínsecas a cada idioma. Por lo tanto, no creemos que los productores suelan limitar la capacidad creativa de la obra por miedo a no superar las fronteras lingüísticas y culturales. A este respecto, es curioso el caso de los Hermanos Marx, que se preocupaban por no hacer chistes demasiado locales con el fin de que sus giras por todo Estados Unidos tuvieran éxito. Sin embargo, estas medidas no fueron suficientes para lograr el éxito en otro país con el mismo idioma pero diferente cultura: Reino Unido (cf. Bego 2001: 35). 


\subsection{Los juegos de palabras en el cine}

Para transmitir toda la fuerza cómica del original, el traductor debe detectar todos los juegos de palabras, esto es, debe percibir las incongruencias del enunciado y ser capaz de reinterpretar el mensaje. El proceso de interpretación del humor se puede resumir de la siguiente manera: los significados que se han ido activando durante el procesamiento de información quedan descartados por una incongruencia, es decir, las cargas semánticas no encajan con el contexto, por lo que el receptor deduce que hay una ambigüedad intencionada y vuelve a interpretar el enunciado teniendo en cuenta su carácter humorístico.

Esta tarea no resulta tan sencilla como pudiera considerarse a priori. En las comedias de los Marx uno de los factores que influyen en la invisibilidad de los juegos de palabras es el diacrónico; el paso de las décadas ha eliminado algunos de los significados explotados en las unidades polisémicas, lo que dificulta la comprensión de los enunciados. Por esta razón, el traductor debe permanecer atento a las diversas pistas que ofrece la versión original y que marcan los pasajes humorísticos. Estas señales pueden ser comunes a todo acto de comunicación o exclusivas del texto fílmico. Las primeras las constituyen los significados no verbales de la enunciación, que "sirven para completar, reducir, realzar o anular los significados proposicionales" (Alcaraz 1990: 146). En nuestro corpus, es frecuente que el código visual transmita información quinésica para explicitar un juego de palabras; por ejemplo, Groucho suele elevar las cejas cuando sus comentarios incluyen insinuaciones de contenido sexual. Además, el texto fílmico dispone de señales exclusivas, entre las que destacan las restricciones visuales y las risas enlatadas. Estas manifestaciones emplean la imagen o la pista de audio para indicar pasajes humorísticos y condicionan la técnica de traducción pues, de no transmitirse una carga humorística en la versión meta, se producirá el poco deseado ruido semiótico, es decir, el espectador observará una incoherencia o un desequilibrio entre los códigos de significación del producto audiovisual.

Otra característica propia de la traducción audiovisual que afecta sustancialmente al trasvase de los juegos de palabras es el ritmo: "El avance implacable de los estímulos en una película añade un esfuerzo extra a la memoria y a los procesos de inferencia del espectador" (Bordwell 1996: 33). Los productos audiovisuales imponen una velocidad que dificulta la presencia de complicados juegos lingüísticos que requieran un esfuerzo elevado de la audiencia meta. No hay que olvidar que el receptor está dispuesto a hacer el esfuerzo de procesar la información a cambio de una recompensa en forma de implicaciones contextuales (cf. Sperber $\&$ Wilson 1982) o del prometido efecto 
humorístico. Sin embargo, dicho proceso requiere tiempo. Un juego de palabras excesivamente complejo exigirá un trabajo por parte del receptor que se traducirá a su vez en un tiempo del que no dispone. De modo que, frente a otros soportes -como pueda ser el libro, que permite detenerse y reflexionar sobre lo leído-, los productos cinematográficos imponen un ritmo ágil de interpretación. Es cierto que los vídeos y DVD permiten la detención de la imagen, pero resultaría molesto y contraproducente tener que parar constantemente el reproductor con el fin de descubrir el efecto cómico.

Además, el medio en que se desarrolla la TAV imposibilita una de las soluciones para los juegos de palabras: las notas a pie de página. Éstas eliminan el efecto y obstaculizan la fluidez del texto pero evitan, mediante la explicación del problema, la extrañeza del receptor ante la incoherencia del texto. La ausencia de espacio para explicaciones en el texto audiovisual impide que los juegos lingüísticos sean solucionados con este recurso.

Por último, el hecho de que el doblaje elimine la pista sonora original permite -siempre que no haya restricciones visuales que lo impidan- la adopción de técnicas de traducción imaginativas — que se alejan del texto original y que suelen ser necesarias para solucionar los problemas que surgen en el trasvase del humor - sin que la audiencia sea consciente de la modificación y no realice, en consecuencia, críticas centradas, fundamentalmente, en algunos aspectos lingüísticos tangenciales.

\section{El doblaje de las restricciones visuales}

A la hora de traducir, siempre que no haya paralelismos entre las lenguas en juego y que sea necesario manipular el texto origen para lograr el efecto perlocutivo, la redundancia semántica propia de las restricciones visuales obstaculiza la traducción, pues el espectador meta recibe información adicional sobre el texto origen. Por tanto, el hecho de que el espectador meta reciba tanto la traducción de la palabra como el mensaje visual original puede suponer una limitación considerable del margen de maniobra del traductor. Debido a que, por lo general en cine - a diferencia de otros medios como pueda ser la publicidad - la imagen no se modifica, el texto meta debe ser acorde con ésta, tratando de expresar por el medio acústico lo que se ve o, al menos, de no contradecirla. Evidentemente, el problema surge cuando "en algún momento en la transferencia de información se produce una ruptura en esa simbiosis de códigos que se daba de modo fluido en el producto origen" (Díaz-Cintas 2001: 122).

Las técnicas a las que se recurre para la traducción de un juego de palabras son de lo más dispares y abarcan desde el empleo de los mismos recursos del 
original hasta la omisión del mismo, pasando por la recreación. Estas opciones pueden deberse bien al paralelismo etimológico entre las lenguas, bien al esfuerzo creativo del traductor. Es decir, encontramos tanto juegos de palabras sin restricción lingüística, como otros con restricción lingüística (cf. Brehm 2005). Los primeros se trasvasan con facilidad, mientras que los segundos requieren el ingenio y la creatividad del traductor. Esta manipulación del texto original puede suponer una modificación semántica que presenta a su vez diversos grados; concretamente, la carga semántica en el texto meta puede ser idéntica, similar o distinta de la original. Por otro lado, cuando no se logra trasvasar la comicidad (ya sea porque pasa desapercibida, por presión temporal u otras causas de diversa índole), la traducción puede mostrar una frase neutra que pierde todo rastro de humor, o bien una traducción literal, que puede provocar la neutralidad o la incoherencia con el contexto.

En un trabajo previo (Martínez-Tejerina 2008), después de analizar un corpus de 240 casos de explotación humorística de la polisemia, propusimos la siguiente taxonomía de técnicas, que son las que mantenemos en el presente análisis:

- Traducción literal por unidad polisémica.

- Traducción literal por unidad no polisémica.

- Neutralización.

- Sustitución.

- Recreación.

- Omisión.

Estas seis técnicas de traducción pueden provocar resultados de lo más diverso (la misma carga semántica, un efecto humorístico análogo, la incongruencia, el ruido semiótico, la neutralidad, la multiplicidad semántica, etc.), que se deben a que cada una de ellas se centra en diferentes planos del discurso, con el fin de trasvasar unos en detrimento de otros. Este fenómeno demuestra que la traducción no puede trasvasar absolutamente todas las características del texto origen y, menos aún, de las partes más vinculadas al lenguaje o la cultura original, por lo que se ve obligada a renunciar a características que resultan menos relevantes en cada contexto. Las tres peculiaridades fundamentales que encontramos en el texto origen son la forma, el recurso humorístico y el efecto perlocutivo.

A la hora de valorar estas técnicas de traducción, determinar cuándo se ha trasvasado el efecto y cuándo no resulta problemático, fundamentalmente porque la recepción del humor depende tanto de factores contextuales, como de la valoración individual. Este análisis es cuantitativo, no cualitativo, por 
lo que no nos aventuramos a analizar qué versión produce más humor, sino a comentar si ha habido una intención humorística por parte del traductor (sea ésta exitosa o no desde nuestro punto de vista). Podemos señalar que, en términos generales, la carga humorística se trasvasa en tres de los recursos traducción literal por unidad polisémica, sustitución y recreación- mientras que interpretamos que se pierde en otras tres — traducción literal por unidad no polisémica, neutralización y omisión-.

Así pues, la traducción literal polisémica trasvasa tanto la forma, como el efecto y el recurso; la traducción literal no polisémica conserva el plano formal del texto origen, pero introduce una forma ajena en el texto meta; la neutralización renuncia tanto a la forma, como al efecto y al recurso, para expresar un mensaje neutral, que pase desapercibido; la sustitución logra trasvasar recurso y efecto, cambiando la forma, al menos parcialmente; la recreación obtiene un efecto perlocutivo análogo modificando el recurso y la forma (al menos parcialmente); por último, la omisión renuncia a cualquier tipo de trasvase.

De modo que el efecto se trasvasa mediante tres técnicas: la traducción literal polisémica, la sustitución y la recreación; el recurso se conserva en otras dos: la traducción literal polisémica y la sustitución; y la forma se mantiene completamente en las dos formas de traducción literal (aunque en la no polisémica la forma introducida es ajena a la lengua meta) y parcialmente en algunos ejemplos de sustitución y recreación (cf. Figura 1).

\begin{tabular}{|c|c|c|c|}
\hline & FORMA & RECURSO & EFECTO \\
\hline $\begin{array}{l}\text { TRADUCCIÓN } \\
\text { LITERAL } \\
\text { POR UNIDAD } \\
\text { POLISÉMICA }\end{array}$ & $\mathrm{X}$ & $\mathrm{X}$ & $\mathrm{X}$ \\
\hline $\begin{array}{l}\text { TRADUCCIÓN } \\
\text { LITERAL POR } \\
\text { UNIDAD NO } \\
\text { POLISÉMICA }\end{array}$ & $\mathrm{X}$ (incorrecta) & & \\
\hline \multicolumn{4}{|l|}{ NEUTRALIZACIÓN } \\
\hline SUSTITUCIÓN & (X parcial) & $\mathrm{X}$ & $X$ \\
\hline RECREACIÓN & (X parcial) & & $X$ \\
\hline OMISIÓN & & & \\
\hline
\end{tabular}

Figura 1. Técnicas de traducción

Usando como criterio la conservación de los distintos planos de la versión original y otorgando prioridad al trasvase del efecto, las técnicas de traducción se podrían graduar en el siguiente orden: traducción literal polisémica 
> sustitución > recreación > neutralización > traducción literal no polisémica $>$ omisión. A continuación se explicarán cada una de estas seis técnicas y se ilustrarán con secuencias de la filmografía de los Hermanos Marx en las que aparecen restricciones visuales.

\subsection{Traducción literal por unidad polisémica}

Con esta etiqueta nos referimos al fenómeno que se produce cuando una unidad de la lengua meta abarca los mismos significados que su equivalente formal en la lengua origen, debido a la coincidencia lingüística. Este término no implica que dichas unidades procedan de una tercera fuente común o que evolucionen de forma similar en la etimología, ya que también incluimos los préstamos en esta categoría.

En una escena de Plumas de caballo (Horse Feathers, 1932) se ve a dos hombres jugando a las cartas en un bar. El que está barajando, le dice al otro:

(1) V.O. Cut the cards.

V.D. Corta.

[Harpo saca un hacha y parte la baraja en dos]

La intervención del personaje se realiza en un contexto lúdico, por lo que se activa la acepción del verbo to cut que expresa 'alzar las cartas para dividir la baraja' (DRAE). No obstante, la actuación de Harpo recupera el significado primario del verbo. En castellano, el verbo 'cortar' abarca los mismos significados, de modo que la traducción literal logra expresar tanto el significado como el efecto.

\subsection{Traducción literal por unidad no polisémica}

Esta técnica consiste en utilizar una unidad en la lengua meta que sólo es equivalente en el plano formal, es decir, sólo expresa una de las cargas semánticas. Esta opción traductora puede dar como resultado dos situaciones diferentes: o bien, aunque no es muy habitual, produce la neutralidad; o bien, provoca una incoherencia en el contexto meta, con lo cual, no sólo se elimina el humor, sino que también puede producir el extrañamiento de la audiencia.

En la comedia Pistoleros de agua dulce (Monkey Business, 1931) un almirante que está buscando a los polizones les comenta a Chico y a Harpo: 
(2) V.O. I'm looking for a couple of mugs.

V.D. Estamos buscando a un par de caraduras.

[Harpo le da dos tazas]

En esta escena, la imagen y la voz muestran la polisemia de la palabra mug ('caradura' y 'tazón'). Así, mientras la intervención del marinero hace referencia de forma despectiva a los polizones, el propio polizón busca un significado totalmente alejado y lo activa mostrando un objeto. En la versión doblada, la traducción literal es deficiente para trasvasar ambas cargas semánticas, lo que no sólo provoca la pérdida del efecto, sino también el ruido semiótico. La incongruencia entre los códigos puede causar bien que la audiencia se extrañe, bien que asuma el comportamiento totalmente absurdo y descabellado de Harpo como algo característico del personaje.

En nuestra opinión, la investigación debería ofrecer soluciones a la realidad práctica y ayudar a mejorarla en la medida de lo posible o, en palabras de Gottlieb (2005: 77),

Descriptive Translation Studies may go in the wrong direction if the prescriptive 'what should be done' is replaced only by the armchair translatologist's 'what is done, and why' and never supplemented by 'what could be done'.

Debido a esta convicción, proponemos opciones traductoras cuyo objetivo es demostrar que trasladar la comicidad y traducir los guiños lingüísticos en la lengua meta no sólo es factible, sino que existen además otras muchas posibilidades. Estas propuestas surgen de distintas fuentes: traducción propia, opciones empleadas en la versión subtitulada, propuestas sugeridas por compañeros de profesión, alumnos de Traducción e Interpretación de la Universitat Autònoma de Barcelona y asistentes al taller sobre traducción del humor celebrado en la Universidad Politécnica de Valencia en 2009. El objetivo no es, ni mucho menos, menospreciar el trabajo del traductor, sino emplear técnicas aplicadas en otros ejemplos de la versión doblada que demuestran la posibilidad de alternativas a las traducciones finalmente realizadas, lo que permite indagar sobre las razones de haber escogido otros caminos traductores.

Volviendo al ejemplo de traducción literal por unidad no polisémica, la reacción de Harpo tal vez podría haber sido más comprensible si el almirante hubiera dicho: Cuando pille a esos polizones me los meriendo.

\subsection{Neutralización}

Ante las dificultades para trasvasar la polisemia y con el objetivo de evitar el extrañamiento de la audiencia, en ocasiones el traductor opta por lograr la 
neutralidad empleando diferentes recursos como la elipsis o el distanciamiento formal o semántico respecto al texto origen. Por lo tanto, esta técnica de traducción consiste en mantener el proceso de comunicación pero vaciando la traducción de efecto humorístico, esto es, se opta por un vacío ilocutivo que permite que la comunicación fluya y que evita a su vez la falta de comprensión de la audiencia.

En la misma película que el ejemplo anterior, minutos después, Chico y Harpo, disfrazados de barberos, tratan de arreglar el bigote de un marinero. Para cortarle lo que le sobra, miden la distancia entre el bigote y la otra punta de la habitación. Chico señala:

(3) V.O. It's about a foot too much

V.D. Treinta centímetros de más.

[Harpo saca un hacha y hace ademán de cortarle un pie al marinero]

Nos encontramos de nuevo con una palabra polisémica cuyos diversos significados son expresados por dos medios diferentes. Chico expresa la medida de distancia con una palabra que Harpo interpreta como una parte del cuerpo. La versión doblada opta por una neutralización que, en esta ocasión, no resulta muy apropiada porque omite la polisemia. Aún así la situación, absurda de por sí, ya garantiza el efecto humorístico. Otra opción, teniendo en cuenta que no es posible trasvasar todos los planos del original, sería emplear una traducción literal que, a pesar de introducir una forma de medida poco utilizada en España, sería entendida por el público meta y mantendría la polisemia: Sobra un pie o Hay un pie de más.

\subsection{Sustitución}

Consiste en el alejamiento semántico de la versión doblada frente a la original, pero manteniendo en el texto meta el mismo recurso que crea el juego de palabras en el texto origen: la polisemia. Teniendo en cuenta que los diálogos se insertan en un contexto fílmico y que la aportación semántica de la imagen es notoria, el alejamiento semántico no suele ser excesivo, ya que se tiende a aludir a rasgos comunes y a conceptos relacionados para evitar incongruencias con los semas visuales y garantizar la coherencia con el contexto. En cualquier caso, se pueden distinguir diversos grados de distanciamiento respecto al original:

- se mantiene una de las cargas semánticas de la unidad polisémica original; 
- se emplean recursos como la hiponimia o la hiperonímia con el fin de trasvasar una carga semántica similar que remite a la del original;

- se recurre a una unidad polisémica distinta con cargas semánticas diferentes a las expresadas en la versión original.

La siguiente escena de Una tarde en el circo (At the Circus, 1939) muestra la explotación de una unidad fraseológica por medio de la imagen. Groucho se presenta a Harpo, que reacciona a su modo particular; en esta ocasión, soplándole un matasuegras en la cara. Groucho responde:

(4) V.O. I'll thank you to keep a civil tongue in your head, not in mine.

V.D. Le aseguro que yo también tengo la lengua larga, cuando es preciso.

En la versión original Groucho desautomatiza la frase hecha to keep a civil tongue (cuyo significado es 'ser educado') y recupera parte del sentido literal 'mantener la lengua dentro de la boca'. En la versión doblada, el traductor opta por una unidad fraseológica que no es equivalente en el plano semántico, pero que logra el trasvase del humor y la congruencia con la imagen. Otra opción acertada es la empleada en la versión subtitulada: Te agradecería que sujetaras esa lengua.

\subsection{Creación autónoma}

Esta opción traductora sustituye el recurso en que se basa el juego de palabras de la versión original por un recurso humorístico distinto como la paronimia, la similicadencia, la descolocación del orden correcto de la frase, la falsa etimología o la ironía. Del mismo modo que en la sustitución, la modificación semántica con respecto al original que conlleva la aplicación de esta técnica humorística autónoma presenta diversos grados.

En Los Hermanos Marx en el Oeste (Go West, 1940), Groucho, Harpo y Chico viajan en una diligencia junto a una señora con un bebé, que llora sin cesar. La madre explica:

(5a) V.O. He can't stand the jerks in the coach.

[Groucho expresa su sorpresa abriendo los ojos de par en par, mientras Harpo y Chico abren la puerta para salir de la diligencia. Groucho les detiene]

V.O. No, wait a minute boys, it was nothing personal. She didn't mean it.

(5b) V.D. Es que no puede resistir los baches.

[...]

V.D. No, un momento, muchachos. Ha dicho baches no cachivaches. 
La palabra jerk es polisémica y en esta escena se activan dos de sus significados; en primer lugar, el contexto del viaje en diligencia recupera el significado de 'sacudida', pero la reacción de Harpo y Chico, y la mirada y comentario de Groucho recuperan un significado coloquial: 'imbécil'. La versión doblada persigue un efecto análogo utilizando no una palabra polisémica, sino una falsa etimología que produce paronimia. Si bien la falta de verosimilitud (es poco probable confundir las dos palabras) minimiza el efecto, hay un claro esfuerzo creativo por parte del traductor.

\subsection{Omisión}

Consiste en la elisión total del mensaje, lo que suele producir un ruido semiótico grave. Este recurso sólo aparece dos veces en el corpus. En Tienda de locos (The Big Store, 1941), se inicia una secuencia con un primer plano de la puerta del despacho de Groucho en el que se anuncia su nombre y cargo. Seguidamente la cámara hace una panorámica vertical y muestra un mensaje que reza:

(6a) V.O. Bloodhounds transfused, fingerprints manicured and gim rummy.

El juego lingüístico se basa en la desautomatización de la palabra compuesta bloodhound ('sabueso'), cuya primera parte significa 'sangre'. Esta carga semántica permite a Groucho decir que se hacen transfusiones de sabuesos. Este inserto no se traduce en la versión doblada, lo que conlleva la pérdida de la carga humorística. Esta omisión no está justificada, ya que las palabras aparecen en primer plano durante varios segundos y en silencio, por lo que el uso de una voz en off o un subtítulo sería plausible. De hecho, el anterior inserto (nombre y cargo del detective) sí se ha traducido mediante una voz en off. Para evitar tanto la pérdida humorística como la incomodidad producida en el espectador por un mensaje sin descodificar, se podría haber explotado la polisemia y paronimia de palabras relacionadas con el campo semántico de la sangre, como por ejemplo:

(6b) V.D. Transfusiones de purasangres, manicura de huellas dactilares y juegos de cartas.

\subsection{Resultados cuantitativos}

La presencia de juegos de palabras con restricciones visuales es habitual en la filmografía de los Marx, pues constituye casi una tercera parte de los juegos de palabras basados en polisemia, concretamente, el 30,8\%. La siguiente tabla muestra el número de ejemplos y el porcentaje en el que la versión doblada 
ha recurrido a cada una de las seis técnicas de traducción de la taxonomía aplicada, expresando, por tanto, la norma traductora ante un fenómeno tan característico de la TAV.

\begin{tabular}{|l|l|c|c|}
\hline \multicolumn{2}{|c|}{ TÉCNICAS DE TRADUCCIÓN } & EJEMPLOS & $\%$ \\
\hline $\begin{array}{l}\text { TRADUCCIÓN } \\
\text { LITERAL }\end{array}$ & POLISÉMICA & 13 & 17,57 \\
\cline { 2 - 4 } & NO POLISÉMICA & 18 & 24,32 \\
\hline NEUTRALIZACIÓN & & 13 & 17,57 \\
\hline SUSTITUCIÓN & & 15 & 20,27 \\
\hline RECREACIÓN & & 13 & 17,57 \\
\hline OMISIÓN & & 2 & 2,7 \\
\hline & TOTAL & 74 & 100 \\
\hline
\end{tabular}

De estas cifras se deduce que la versión doblada logra trasvasar el efecto perlocutivo humorístico en una escasa mayoría de ejemplos (41 veces; 55,4\%). En trece ocasiones (esto es, un 17,57\%), la conjunción de códigos no supone un impedimento porque se da una equivalencia entre los pares polisémicos de las lenguas en juego. Sin embargo, el efecto perlocutivo se logra mayoritariamente gracias al esfuerzo creativo del traductor, que se aleja del texto original en 28 ocasiones $(37,83 \%)$ con el fin de trasvasar el efecto en detrimento de la forma (trece creaciones autónomas y quince sustituciones). No hay que olvidar que la libertad del traductor queda limitada por la redundancia semántica, pues el espectador meta recibe información adicional sobre el texto origen a través del canal visual y, por lo tanto, el texto meta debe ser acorde con éste, tratando de expresar por el medio acústico lo que se ve o, al menos, de no contradecirlo. De este modo, observamos que los juegos de palabras enmarcados en el texto audiovisual retan a la creatividad del traductor, pues es conveniente inventar un recurso humorístico nuevo que esté relacionado además con lo que ocurre en pantalla.

Según nuestro análisis cuantitativo, la comicidad se pierde en casi la mitad de los casos, concretamente en 33 (18 traducciones literales por lexema no polisémico, 13 neutralizaciones y dos omisiones). Curiosamente dos de estos ejemplos son pares equivalentes que, por alguna razón, el traductor ha decidido no traducir de forma literal. Es decir, aparecen dos unidades cuyas formas y significados se podían haber trasvasado literalmente con un resultado satisfactorio, pero que se han traducido por medio de otras técnicas de traducción que eliminan la duplicidad semántica.

La siguiente tabla indica el porcentaje en el que se recurre a las distintas técnicas de traducción en los ejemplos con y sin restricciones visuales, con el 
fin de analizar si el hecho de que el juego de palabras se exprese parcialmente a través de la imagen incide en la norma traductora.

\begin{tabular}{|l|l|c|c|}
\hline \multicolumn{2}{|c|}{ TÉCNICAS DE TRADUCCIÓN (\%) } & $\begin{array}{c}\text { RESTRICCIONES } \\
\text { VISUALES }\end{array}$ & $\begin{array}{c}\text { SIN } \\
\text { RESTRICCIONES } \\
\text { VISUALES }\end{array}$ \\
\hline $\begin{array}{l}\text { TRADUCCIÓN } \\
\text { LITERAL }\end{array}$ & POLISÉMICA & 17,57 & 33,13 \\
\cline { 2 - 4 } & NO POLISÉMICA & 24,32 & 18,67 \\
\hline NEUTRALIZACIÓN & & 17,57 & 10,24 \\
\hline SUSTITUCIÓN & & 20,27 & 18,67 \\
\hline RECREACIÓN & & 17,57 & 18,67 \\
\hline OMISIÓN & & 2,7 & 0,60 \\
\hline
\end{tabular}

Pese a las diferencias que se podrían prever, las técnicas de traducción empleadas en ambos casos presentan porcentajes similares. La solución predominante es la traducción literal (41,89\% y 51,8\% respectivamente). La sustitución y la recreación presentan cifras porcentuales similares, mientras que la neutralización reduce su aparición cuando no aparecen restricciones visuales $(10,24 \%$ frente al $17,57 \%)$. Por último, la omisión tiene una presencia prácticamente insignificante en ambas situaciones.

Los resultados de las técnicas de traducción difieren en mayor medida. La polisemia se trasvasa el $51,8 \%$ de las ocasiones en las que no aparece restricción visual, frente al 37,84\% de las veces en que aparece. Por lo tanto, la multiplicidad semántica se trasvasa un 13,96\% más cuando los significados no se expresan por medio de la imagen.

En cuanto a la traducción del efecto, resulta llamativo que mientras que en los ejemplos sin restricción visual se consigue en un 70,5\%, cuando aparece una restricción visual el humor se reduce a un 55,4\%. Esta reducción del humor se debe fundamentalmente a un aumento del uso de la neutralización (ascenso del $7,33 \%$ ) y de la traducción literal por unidad no polisémica (ascenso del 5,05\%). La divergencia aumenta si descartamos los paralelismos etimológicos. En los casos en los que existe una falta de equivalencia entre ambas lenguas, se pierde la carga humorística en el 44,59\% de las secuencias con restricción visual frente al 29,5\% de las escenas sin restricción visual. Por lo tanto, en las secuencias en que la carga semántica se expresa mediante la imagen, la pérdida humorística aumenta en un 15,09\%. 


\section{Conclusiones}

Si bien este artículo sólo ha analizado el doblaje de trece películas, las cifras que se extraen del mismo parecen demostrar que la existencia de restricciones visuales en las comedias suele provocar un aumento en la pérdida del efecto humorístico, lo que corrobora la idea de que la aparición de restricciones visuales dificulta considerablemente la traducción de los juegos de palabras cuando no se desarrolla el paralelismo etimológico. Esto se debe a que el traductor se ve forzado a expresar o no contradecir el significado que aparece en la pantalla, con el fin de evitar el ruido semiótico y el extrañamiento de la audiencia meta; en otras palabras, está más atado al significado de la versión original o, concretamente, a los posibles significados expresados por la imagen.

La pérdida del humor en los textos audiovisuales en los que aparecen restricciones visuales puede desencadenar consecuencias muy diversas: en ocasiones, el espectador no se percata de ello por razones de diversa índole, por ejemplo, la rapidez de los diálogos; otras veces, esta incoherencia extraña e incomoda al receptor, pues le recuerda que se encuentra ante un producto manipulado; y en otros casos, se produce un fenómeno curioso y es que tales incongruencias provocan igualmente humor. Detengámonos a analizar estas consecuencias.

En primer lugar, la incongruencia puede pasar desapercibida cuando el juego de palabras se desarrolla en una situación de enredo en la que abundan los recursos humorísticos (otros chistes lingüísticos, bromas visuales -caídas, gestos, disfraces, golpes y burlas-, situaciones de enredo o absurdos), lo que resta importancia a la eliminación del efecto o incluso a las contradicciones que se pueden producir entre el código visual y el lingüístico.

En segundo lugar, es probable que esa pérdida del humor provoque ruido semiótico que, si bien puede presentar distintas intensidades (la imagen puede repercutir en mayor o menor grado en la transmisión semántica), hace que el espectador sea consciente de la contradicción entre los códigos, lo que causa su extrañamiento, pues le recuerda que se encuentra ante un producto manipulado, lo que puede provocar la ruptura del acuerdo tácito denominado suspension of disbelief.

Ahora bien, en ocasiones, el espectador cree que esa incongruencia se debe a que el producto es absurdo, lo que genera el efecto humorístico en la audiencia meta, si bien basado en un recurso distinto del original. $\mathrm{Cu}$ riosamente, la predilección por la traducción literal crea unos personajes y situaciones mucho más absurdos para la audiencia meta, que disfruta de sus despropósitos sin saber que la propia traducción al español los ha acrecentado, como otros estudios también han demostrado (Fuentes 2001). Es cierto 
que el humor de los Hermanos Marx se inscribe en el género del absurdo también en la versión original, pero sus disparates suelen basarse en juegos de palabras, es decir, la locura procede de una fuente lingüística con un doble significado comprensible, no aparece sin más como ocurre a veces en la versión doblada. Por lo tanto, la traducción produce la modificación del tipo de humor de los Marx: el texto origen se basa principalmente en la resolución de la incongruencia y el texto meta en el absurdo, en otras palabras, ambos explotan la incongruencia, pero en el primer caso ésta se resuelve y en el segundo no. Resulta curioso que la traducción haya provocado estos cambios en las características fundamentales del humor de los Marx y, a su vez, haya logrado extender su obra por todo el mundo con gran éxito.

Uno de los factores que quizá fomentaron esta aceptación fue la cooperación propia de la audiencia de comedias. Al incluir una película dentro del género de la comedia se destaca el efecto emocional al que aspira y, por lo tanto, provoca en el receptor la actitud necesaria para interpretar la incongruencia como humor, es decir, el contexto ayuda al interlocutor a decidir la reacción que merece la incongruencia. Del mismo modo que los cómicos preparan a sus espectadores para la recepción del chiste, la audiencia española sabe que va a ver una comedia.

Por otro lado, el público actual sabe que esta comedia es de los Hermanos Marx y la idea generalizada en España hoy en día es que estos cómicos cultivan el humor del absurdo. Tales conocimientos fomentan la aceptación de un texto cargado de incongruencias y, en consecuencia, favorecen el éxito de la traducción literal como fuente de absurdos.

Otro de los factores que pudo incidir en este éxito es el monopolio del cine hollywoodiense en aquel entonces y que en cierta medida hoy perdura. A este respecto, Chiaro (2006) compara la trascendencia de los Hermanos Marx con la divulgación del cómico italiano Totò que, siendo contemporáneo de los Marx y con un estilo similar, nunca superó las fronteras de su país, a pesar de una subtitulación "perfectly adequate" (Chiaro 2006: 204).

En cualquier caso, el hecho de que la audiencia meta incluya la filmografía de los Hermanos Marx dentro del género de la comedia demuestra que, al menos desde el punto de vista descriptivista y funcional, el humor de los Marx es traducible. Aunque en el nivel estrictamente microtextual encontramos multitud de ejemplos que no se trasvasan con éxito, el objetivo de su obra -hacer reír- sí se logra. 


\section{Bibliografía}

Agost, Rosa. (1999) Traducción y doblaje: palabras, voces e imágenes. Barcelona: Ariel.

Alcaraz, Enrique. (1990) Tres paradigmas de la investigación lingüística. Alcoy: Marfil.

ATTARDO, Salvatore \& Victor Raskin. (1991) "Script theory revis(it)ed: joke similarity and joke representation model". En: Attardo, Salvatore et al. (eds.) 1991. Humor, the International Journal of Humor Research. Mouton de Gruyter. Volumen 4. pp. 293-348.

BEGO, Mark. (2001) The Marx Brothers. Harpenden: Pocket Essentials.

BREHM CRIPPS, Justine. (2005) "Entre la espada y la pantalla. Restricciones y grados de dificultad en la traducción de juegos de palabras para el doblaje". En: Zabalbeascoa, Patrick; Laura Santamaria \& Frederic Chaume (eds) 2005. La traducción audiovisual: investigación, enseñanza y traducción. Granada: Comares. pp. 189-200

BordWEll, David. (1996) La narración en el cine de ficción. Barcelona: Paidós, 2006.

Castro Roig, Xosé. (2001) "Reflexiones de un traductor audiovisual". En: Sanderson, John D. (ed.) 2001. ¡Doble o nada! Actas de las I y II Jornadas de doblaje y subtitulación. Alicante: Publicaciones de la Universidad de Alicante. pp. 39-44.

Chaume, Frederic. (2004) Cine y traducción. Madrid: Cátedra.

CHAVES, María José. (2000) La traducción cinematográfica: el doblaje. Huelva: Universidad de Huelva.

CHIARO, Delia. (2000) “'Servizio completo'? On the (un)translatability of puns on screen". En: Bollettieri Bosinelli, Rosa M.; Christine Heiss; Marcello Soffritti \& Silvia Bernardini (eds.) 2000. La traduzione multimediale: Quale traduzione per quale testo? Bologna: CLUEB (Cooperativa Literaria Universitaria Editrice Bologna). pp. 27-42.

ChiAro, Delia. (2005) "Suspension of disbelief or mediatic diglossia? How Italians perceive dubbese". Ponencia presentada en el congreso MuTra: Challenges of Multidimensional Translation, celebrado en Saarbrücken entre el 2 y 6 de mayo de 2005.

Chiaro, Delia. (2006) "Verbally Expressed Humour on Screen: Reflections on Translation and Reception". En: Desblache, Lucile et al (eds) 2006. Jostrans - The Journal of Specialised Translation. Issue 6. Versión electrónica: <http:// www.jostrans.org/issue06/art_chiaro.php>.

Chion, Michel. (1990) L'audiovision. Paris: Nathan.

Delabastita, Dirk. (1989) "Translation and Mass Communication: Film and T.V. Translation as Evidence of Cultural Dynamics". Babel. 35:4. pp. 193-218. 
Díaz CinTAS, Jorge. (2001) "Aspectos semióticos en la subtitulación de situaciones cómicas”. En: Pajares, Eterio; Raquel Merino \& José M. Santamaría (eds.) 2001. Trasvases Culturales 3: Literatura, cine, traducción. País Vasco: Servicio Editorial de la Universidad del País Vasco. pp. 119-130.

DíAz CinTAS, Jorge. (2003) Teoría y práctica de la subtitulación. Ariel: Barcelona.

FREUD, Sigmund. (1905) El chiste y su relación con el inconsciente. Madrid: Alianza, 1984.

FUENTES LUQUE, Adrián. (2001) La recepción del humor audiovisual traducido. (Estudio comparativo de fragmentos de las versiones doblada y subtitulada al español de la película Duck Soup, de los Hermanos Marx). Granada: Editorial Universidad de Granada.

GotTlieb, Henrik. (2005) Screen Translation. Eight studies in subtitling, dubbing and voice-over. Copenhagen: Center for Translation Studies, Department of English, University of Copenhagen.

HuRTADO AlbiR, Amparo. (2001) Traducción y traductología. Introducción a la traductología. Madrid: Cátedra.

IVARSSON, Jan. (1992) Subtitling for the Media. Stockholm: Ljunglöfs Offset AB.

MARTínEZ SierRA, Juan José. (2008) Humor y traducción. Los Simpson cruzan la frontera. Castelló de la Plana: Publicacions de la Universitat Jaume I.

MARTÍNEZ-TEJERINA, Anjana. (2008) La traducción para el doblaje del humor basado en la polisemia: los Hermanos Marx cruzan el charco. Tesis doctoral. Universidad de Alicante.

RABADÁN, Rosa. (1991) Equivalencia y traducción. León: Secretariado de Publicaciones de la Universidad de León.

RASKIN, Victor. (1985) Semantic Mechanisms of Humor. Dordrecht-Boston-Lancaster: D. Reidel.

REDFERn, Walter. (1984) Puns. London: Penguin Books [2000].

SPERBER, Dan \& Deirdre Wilson. (1982) "Mutual Knowledge and Relevance in Theories of Comprehension". En: Smith, Neil (ed.) 1982. Relevance: Communication and Cognition. London: Academic Press. pp. 61-85.

VARIOS AUTORES. 1837. Diccionario de la Real Academia Española. Versión electrónica: <http://www.rae.es> 2010.

Whitman, Candace. (2001) "Cloning Structures: The Return of the Movie Mutants". En: Agost, Rosa \& Frederic Chaume (eds.) 2001. La traducción en los medios audiovisuales. Castellón: Publicaciones de la Universitat Jaume I. pp. 143-158.

\section{Filmografía}

Animal Crackers (Victor Heerman, 1930). El conflicto de los Hermanos Marx. The Big Store (Charles Reisner, 1941). Tienda de locos. 
At the Circus (Edward Buzzell, 1939). Una tarde en el circo.

The Cocoanuts (Robert Florey y Joseph Santley, 1929). Los cuatro cocos.

A Day at the Races (Sam Wood, 1937). Un día en las carreras.

Duck Soup (Leo McCarey, 1933). Sopa de ganso.

Go West (Edward Buzzell, 1940). Los Hermanos Marx en el Oeste.

Horse Feathers (Norman Z. McLeod, 1932). Plumas de caballo.

Love Happy (David Miller, 1949). Amor en conserva.

Monkey Business (Norman Z. McLeod, 1931). Pistoleros de agua dulce.

A Night at the Opera (Sam Wood, 1935). Una noche en la ópera.

A Night in Casablanca (Archie Mayo, 1946). Una noche en Casablanca.

Room Service (William A. Seiter, 1938). El hotel de los líos.

\section{BIONOTE / NOTA BIOGRÁFICA}

\section{Anjana Martínez Tejerina}

Anjana Martínez Tejerina, PhD, obtained her Degree in Translation and Interpretation at the University of Alicante in 2003 and was certified as a sworn translator in 2004, when she received a Leonardo grant to work as a teaching assistant in London for two years. She finished her Master's in Screen Translation at the Universitat Autònoma de Barcelona in 2007 and taught two subjects at that university a year later. She became a PhD in 2008. Nowadays, she is working as a freelance audiovisual translator, she teaches several subjects at Universitat Pompeu Fabra, where she has been an adjunct professor since 2010 and she is a member of the research group CAIAC (Universitat Autonoma de Barcelona). Besides, she collaborates as a teacher in the Postgraduate Programme in Audiovisual Translation at the IDEC-UPF and as a tutor and external evaluator in the Master's in Screen Translation at the Universitat Autònoma de Barcelona.

La doctora Anjana Martínez Tejerina se licenció en Traducción e Interpretación en la Universidad de Alicante en 2003 y obtuvo el título de traductora jurada en 2004, año en el que también le fue concedida una beca Leonardo para trabajar como auxiliar de conversación en Londres. Realizó un máster en Traducción Audiovisual en la Universitat Autònoma de Barcelona en 2007, universidad en la que trabajó como profesora asociada al año siguiente, siendo responsable de dos asignaturas de la Licenciatura de Traducción. Obtuvo el título de doctor en 2008. En la actualidad trabaja como traductora autónoma en el ámbito de la subtitulación, imparte varias asignaturas en la Universitat Pompeu Fabra, donde es profesora asociada desde 2010, y es miembro del 
grupo de investigación CAIAC (Universitat Autònoma de Barcelona). Además, colabora como profesora en el Postgrado de Traducción Audiovisual del IDEC-UPF y como tutora y evaluadora externa en el Máster en Traducción Audiovisual de la UAB. 